\title{
Artes e memórias na Ilha de Santa Catarina: expressão visual e performance musical na trajetória de Valdir Agostinho
}

Arts and memories in Santa Catarina's Island: visual expression and musical performance in the Valdir Agostinho's life trajectory

Luciano Py de Oliveira*

Palavras-chave: Valdir Agostinho História oral Artes visuais

Keywords:

Valdir Agostinho

Oral History

Visual Arts
Resumo: Este artigo apresenta parte da trajetória artística do catarinense Valdir Agostinho, com base no seu acervo pessoal, que reuniu diferentes tipos de documentos, como evidência de sua carreira. Dentre as artes visuais, destaca-se a pandorga, objeto que adquire status de obra de arte, escolhido como amostragem e análise neste trabalho, que se integra à pesquisa ampliada, como parte do projeto de tese. Foram escolhidas três pandorgas, em função de ênfases e perspectivas distintas: a representação autobiográfica; a temática da natureza e do meio ambiente; as tradições orais da Ilha de Santa Catarina, articuladas ao desenvolvimento de oficinas de arte. $\mathrm{O}$ artigo pretende demonstrar que o trânsito pela cidade permitiu ao artista vivenciar diferentes redes de sociabilidade, em direção à modernidade, como na pandorga "O Roqueiro"; consolida-se como artista profissional com a pandorga "Ecologia no ar", adotando essa temática como um dos eixos principais de seu trabalho; retorna para a Barra da Lagoa, seu bairro nativo e passa a adotar outro eixo temático, a cultura popular, assim como fez seu mestre Franklin Cascaes, o que pode ser percebido na pandorga "Flor de renda".

Abstract: This article intends to present a sample of Valdir Agostinho's artistic trajectory. The research started in the artist's personal archive, which gathered different types of documents, as a evidence of his career. Among his production, in Visual Arts, we highlight the pandorga ('kite'), object that acquires status of art work, chosen as sampling and analysis in this article, which integrates the expanded research as part of thesis project. There were selected three pandorgas, according to different emphases and perspectives: the autobiographical representation; the theme of nature; the environment and the Oral Tradition of Santa Catarina's Island, articulated to the development of art workshops. The article aspire to demonstrate that the transit through the city allowed the artist to experience different sociability networks towards modernity, as in the kite named "O Roqueiro"; the professional artist's consolidation came with the kite "Ecologia no ar", embracing this theme as a landmark of his work; the return to Barra da Lagoa, his native neighborhood when he starts to adopt another thematic axis, the popular culture, like his master Franklin Cascaes, observed in the kite "Flor de renda".

Recebido em 27 de maio de 2019. Aprovado em 11 de julho de 2019.
Valdir Agostinho é um catarinense natural da Barra da Lagoa, bairro localizado na Ilha de Santa Catarina, parte insular do município de Florianópolis/SC. Sua diversificada atuação justifica a assumida condição de multiartista; pois, além das artes visuais, somam-se produções musicais e performances carnavalescas em sua carreira. Destacam-se, nesta trajetória, a elaboração de pandorgas, como objetos de arte, uma variante do brinquedo conhecido como pipa ou papagaio ${ }^{1}$. Tais produções são objetos tridimensionais feitos de materiais diversos, que eventualmente originam-se da reciclagem. Este artigo pretende apresentar, como reflexão, uma amostragem do universo documental e de análise na pesquisa de tese em desenvolvimento, "Pandorgas parabólicas, bernúncia reciclada:

\footnotetext{
* Atualmente, cursa doutorado no Programa de Pós-Graduação em História da Universidade do Estado de Santa Catarina (UDESC). Licenciado em Educação Artística com habilitação em música (UDESC). Mestre em Etnomusicologia (UFBA). Professor de Educação Musical do Colégio de Aplicação - Centro de Educação - Universidade do Federal de Santa Catarina (UFSC). E-mail: <lucianopy@gmail.com>.
} 
fragmentos de memória e identidade em Valdir Agostinho (1970-2010)". O artista reuniu, ao longo de sua vida, um acervo documental sobre a sua carreira nos mais variados formatos: recortes de jornais, livros, folders, fotografias, audiovisuais e obras de arte de sua autoria e de outros autores. Todo este conjunto de fontes encontra-se em seu estúdio de trabalho, ao lado da residência.

As pandorgas, como evidência de sua criação autoral, destacam-se como especificidade no campo artístico, motivo da escolha da amostragem comentada neste trabalho. Para esta análise, foram selecionadas três obras temáticas neste suporte. Os temas são: 1) "O Roqueiro", na qual se percebe sua relação com a música, neste caso, o Rock, em uma representação autobiográfica; 2) "Ecologia no Ar", emerge a natureza e o meio ambiente como referência; 3) "Flor de Renda", que faz menção ao folclore e à cultura popular da Ilha de Santa Catarina.

Além das evidências documentais materiais sobre o acervo, foram realizadas entrevistas orientadas de acordo com a metodologia da História oral (ALBERTI, 2013, p. 157-234). Para a pesquisa de doutorado em andamento, foram realizadas quatro entrevistas com Valdir Agostinho, das quais três serão utilizadas neste artigo (2008, 2009a, 2009b), sendo uma delas (2009a) especialmente voltada à dimensão e importância das pandorgas no conjunto de sua produção artística.

Desde o Renascimento, a escrita foi considerada o meio ideal para a preservação e ativação da memória, devido a qualidades como "legibilidade e transparência", de acordo com pensadores da época. Com o aprofundamento dos estudos sobre a mente humana e, consequentemente, a memória, historiadores contemporâneos passaram a incorporar as imagens como fontes históricas, ao problematizar também a tradição escrita e "descobrir novos acessos ao passado por meio de imagens e monumentos" (ASSMAN, 2011, p. 237). Ao tratar de fontes visuais, Didi-Huberman (1998) destaca que o ato de olhar é carregado de uma pluralidade de significados, definindo uma perspectiva social como ação, além do indivíduo. A partir dessa premissa, discorre o autor sobre alguém que despreza essa multiplicidade de sentidos:
"Esse objeto que vejo é aquilo que vejo, um ponto, nada mais”. Terá assim feito tudo para recusar a temporalidade do objeto, o trabalho do tempo ou da metamorfose no objeto, o trabalho da memória - ou da obsessão - no olhar. Logo, terá feito tudo para recusar a aura do objeto, ao ostentar um modo de indiferença quanto ao que está justamente por baixo, escondido, presente, jacente. E essa própria indiferença se confere o estatuto de um modo de satisfação diante do que é evidente, evidentemente visível: "O que vejo é o que vejo, e me contento com isso [...].(DIDI-HUBERMAN, 1998, p. 39).

Exemplo desta via de interpretação pode ser observado na série de pandorgas assemelhadas ao formato de mandalas ${ }^{2}$, que foram recebidas pelo público como tendo uma 'visualidade oriental', o que não havia sido a intenção inicial do artista. Comenta: "Gente do Mocotós, chegando a ficar parado na minha pandorga, e perguntar se veio da Índia [...] eu até não gostava [...]. Então eu já tinha uma coisa indiana, eu já vim com uma visão colorida, a mandala" (AGOSTINHO, 2009a). ${ }^{4}$ As fontes utilizadas neste artigo, para além dos objetos construídos como pandorgas, passam por outro filtro de comunicação: a reprodução fotográfica. Jacques Rancière (2018) alerta para as peculiaridades da fotografia, uma técnica de representação visual que é quase onipresente nos dias de hoje, mas que foi introduzida recentemente na história humana, se considerarmos a longa duração de representações bidimensionais feitas manualmente, como desenhos e pinturas. Por mais que exista a intervenção do fotógrafo, a fotografia não tem uma "memória", no sentido de captar a luminosidade que se espalha por tudo e por todos, sem distinção. Diferentemente das pinturas históricas, que procuravam retratar um evento passado com matizes de sua contemporaneidade. Tal percepção dialoga com a análise feita por Koselleck sobre a obra Die Alexanderschlacht, ("A batalha de Isus", 1528), de Albert Altdorfer, quando retrata o evento, ocorrido em 333 a.C, reproduzindo-o com riqueza de detalhes, o qual também era historiógrafo da Corte. A partir da obra descrita, é possível perceber que "[...] Alexandre e Maximiliano (Atldorfer 
pintou o quadro para esse último) assemelhamse de maneira exemplar" (KOSELLECK, 2006, p. 22). Em uma situação análoga, Rancière analisa uma foto da família real russa, do início do século $\mathrm{XX}$, com a mesma função de representação das grandes personalidades políticas e suas ações. Contudo, a máquina captura a todos, nobres e plebeus, importantes e anônimos. Mesmo que não exista uma aproximação ou equidade entre eles, compartilharam a mesma imagem representada.

Porque, para que ela mesma exista, é preciso que eles tenham algo em comum: o pertencimento a um mesmo tempo, justamente aquele que denominamos história - um tempo que não é mais o simples receptáculo indiferente das ações memoráveis, destinadas aos que devem ser memoráveis por sua vez, mas o tecido mesmo do agir humano em geral; um tempo qualificado e engajado, que traz promessas e ameaças; um tempo que iguala todos que lhe pertencem: os que pertencem e os que não pertencem à ordem da memória. (RANCIÈRE, 2018, p. 19).

O advento da fotografia como uma reprodução mais "fidedigna" da realidade acaba por se tornar um importante meio para a ativação de memórias, "[...] pois é considerada o indício mais seguro de um passado que não existe mais, como estampa [Abdruck] remanescente de um momento passado" (ASSMAN, 2011, p. 238). Como será discutido mais adiante, as reproduções fotográficas selecionadas para este artigo são vestígios de obras e lugares que marcaram a trajetória do artista.

A sistemática de arquivamento e organização do acervo de Valdir Agostinho apoia-se na lógica do indivíduo, que seleciona aquilo que julga ser importante o suficiente para ser preservado. "Passamos assim o tempo a arquivar nossas vidas: arrumamos, desarrumamos, reclassificamos. Por meio dessas práticas minúsculas, construímos uma imagem, para nós mesmos e às vezes para os outros" (ARTIÈRES, 1998, p. 10). Além da dimensão individual aqui ressaltada, destaca-se que, no caso de um artista, torna-se necessário documentar sua passagem autoral pelo mundo, de onde vem seu reconhecimento.
Valdir Agostinho preocupou-se com isso, pois vem juntando documentos ao longo de sua carreira, organizando os que julga mais importantes em pastas classificatórias, as quais que denomina "buques", e que equivalem em função ao seu portfólio ${ }^{5}$. Em outra categoria, estão os documentos audiovisuais, dos quais ele possui algumas mídias analógicas, em suportes físicos como VHS, CDs ou DVDs. No entanto, muitos destes registros já se encontram em arquivos digitais, frequentemente acessados por músicos com quem ele desenvolveu diferentes trabalhos artísticos e/ou relacionados, e que podem ser localizados em computadores de uso pessoal e nas redes virtuais. $\mathrm{O}$ artista não faz uso cotidiano de computadores nem tem acesso à internet em sua casa. Porém, sua trajetória e produção, atualmente, encontram-se disponíveis em diversas plataformas digitais, que acabam por representar, em seu conjunto, uma espécie de repositório, reunindo falas soltas, entrevistas dadas e performances aleatórias de sua autoria. Todo este material documental pode ser localizado considerando o entorno da atuação de Valdir Agostinho, diante de seu contato com diversas pessoas, entre fãs, produtores, colegas artistas e amigos.A escolha de um modo de vida peculiar, integrado à natureza, define o universo à parte construído por Valdir Agostinho, em uma relação cosmogônica entre sua atividade profissional e artística, espécie de definição ontológica percebida em sua relação com o mundo e tudo o que resulta de sua atuação. Reside em uma extensa área verde, que se inicia na margem da SC-406, rodovia de acesso ao leste e norte da Ilha de Santa Catarina. A propriedade se estende ao leste, em elevação, em direção ao Parque Municipal da Galheta. A praia de mesmo nome situa-se entre duas outras, a Praia da Barra da Lagoa e a Praia Mole, muito populares e bastante frequentadas na alta temporada. Diante disso, pode-se aferir que a propriedade se encontra em um perímetro de grande interesse especulativo imobiliário, tendo em vista o turismo da região. $\mathrm{O}$ intenso impacto ambiental provocado pela ocupação desordenada deste lugar e de outras áreas em Florianópolis pode ser observado como uma das principais temáticas de sua obra. 
Tendo nascido na Barra da Lagoa, em 1956, Valdir Agostinho morou no Centro da capital catarinense nos anos 1970, quando se mudou para a casa de uma tia, com a decisão de estudar. Contrariava o modo de vida da família, que até então, estava condicionada à atividade da pesca como prática cultural e meio de sobrevivência.

Opapai ficou muito triste, né [...] Chegou a chorar, porque eu era pescador muito bom. Eu já pescava com ele nessa idade. Pulava duma canoa pra outra, se não tinha patrão ${ }^{6}$ na canoa eu substituía, em alto-mar. Entrava na boca da Barra sendo o patrão da canoa, não podia ser um menino, tinha que ser verdadeiro um homem. E eu um menino, ali, o papai botava confiança em mim. E o papai, então, perdeu um pescador. Ele não me 'guentou', me deixou ir morar com a minha tia na Prainha'. Virado pra ponte Hercílio Luz. Ali era fantástico pra mim. (AGOSTINHO, 2008). ${ }^{8}$

E a minha mãe, todos choraram. Foi uma decisão minha que eu queria ir pra cidade e não para o Rio Grande do Sul com 18 anos. Com 14, então, eu fui pra cidade e menti que tinha emprego. Mentira, eu tinha muito dinheiro, porque eu era um grande vendedor de siri. Eu pegava siri, comprava siri. Eu puxei negociante igual o papai, eu acho que eu tenho o espírito empreendedor do papai. Mas... E vendia muito siri para turista. Que a nossa praia fabulosa era Praia das Areias, que é a Praia das Rendeiras. Era a única praia de Floripa. Não tinha mais praia para turista nenhum ir, ninguém queria conhecer a Joaquina, naquela época. Sei lá, em... 70? Não sei. 78, 77, 80? Então, uma praia famosa e os carros paravam, porque não dava para passar [...] parece mentira né? Que não tinha estrada, era na areia [...] Eu tinha muito dinheiro quando criança, ninguém da minha casa ganhou dinheiro que nem eu. Ninguém. Porque eram dois balaios aqui de siri [gesticula demonstrando como carregava os balaios], e eu voltava com aquele bolão de dinheiro e com os balaios vazios. (AGOSTINHO, 2008). ${ }^{9}$ Eu queria ir para Floripa, porque eu gostava de Florianópolis, achava lindo. "Pô, sair daqui, desse meio de mato!", da Barra, que eu tava numa toca, no meio do mato. Lindo, maravilhoso. Mas chegar a morar numa cidade? Putz, nós éramos manezinhos [...].então, eu era uma pessoa chique. Tava na cidade, mas não por isso. Porque [...].todo mês eu vinha para Barra [...]. Aí a minha mãe me recebia muito bem, fazia uma comida especial para mim. E papai me recebia bem, meus irmãos [...]. (AGOSTINHO, 2008). ${ }^{10}$

Tal atitude teve como resultado uma experiência de vida diferenciada dos pais e irmãos. A presença constante dos automóveis, a modernidade na arquitetura dos prédios, a imponência da Ponte Hercílio Luz encantaram o jovem de 14 anos que vinha do interior da Ilha. Para se manter, teve vários empregos, como frentista em posto de gasolina, atendente de lanchonete e office-boy na galeria de arte de Beto Stodieck (colunista e proprietário da galeria de arte Studio A/2) ${ }^{11}$. Valdir Agostinho comenta, ao lembrar-se do convívio com os artistas que frequentavam o local, "[...] eu peguei um choque cultural muito grande quando cheguei em Floripa. Obras de arte, com perfeição" (AGOSTINHO, 2009a). ${ }^{12}$ Essa experiência profissional possibilitou que pudesse ter o próprio negócio, bastante rentável, associado ao mercado da arte, a Garapuvu Molduras (AGOSTINHO, 2009b). ${ }^{13}$ A partir da experiência mais intensa com o meio urbano e contemporâneo, alternou sua permanência entre o Centro e a Barra da Lagoa. Na medida em que seu trabalho artístico se intensificou, tornou-se mais profícuo, passando a viver desta atividade, entre as artes visuais e a música. Tornando-se mais conhecido em sua obra, outras oportunidades de atuação e divulgação estabeleceram-se, a partir do fomento cultural do Município e do Estado, o que possibilitou que chegasse a outros países, como Argentina, EUA e França. Em épocas de crise, refugiava-se em sua propriedade na Barra da Lagoa. O aluguel de duas casas pequenas, neste terreno, ainda hoje lhe possibilita uma renda de subsistência. Manteve sua propriedade naturalmente preservada, repleta de bambuzais ${ }^{14}$, um importante material utilizado na confecção das pandorgas. O bambu contrasta com os demais materiais recicláveis utilizados como recurso e princípio em sua obra. No caso das matérias-primas reutilizadas e presentes nas artes visuais de Valdir Agostinho, destaca-se que se 
encontram ali a partir do recolhimento feito pelo próprio artista, em objetos depositados nas praias, ruas e aterros sanitários da cidade. Somandose a isso, a preocupação ambiental exemplificase também em sua atividade como educador, ao promover oficinas de arte para alunos de ensino fundamental e médio. Ao optar pela arte como meio de vida e como uma forma de lutar em favor da preservação do meio ambiente, é possível traçar um paralelo com aquilo que François Hartog chamou de "fendas do presente":

Em meados dos anos 1970, outra fenda manifesta-se no presente. Ele começa a se mostrar preocupado com a conservação (de monumentos, de objetos, de modos de vida, de paisagens, de espécies animais) e ansioso em defender o meio ambiente. Os modos de vida local e a ecologia, de temas exclusivamente contestatórios passaram a ser temas mobilizadores e promissores. (HARTOG, 2014, p. 151).

É possível afirmar que essa percepção sobre o tempo alcançou as sociedades ocidentais como um todo, a partir de meados da década de 1950 e período de nascimento e infância de Valdir Agostinho. Protagonizar o ato de sair para o Centro da cidade para estudar foi decisivo para determinar o horizonte de expectativa que o aguardava, mudando o rumo de seu futuro, que poderia ser predeterminado pelo entorno social e familiar. Este sujeito, inserido na contemporaneidade, desperta para a preocupação com o meio ambiente, ameaçado pelo progresso capitalista e seu pretenso domínio sobre a natureza. Ao retornar para a Barra da Lagoa e optar por viver no meio da natureza, parece ter criado um "simulacro" para outro tempo, que lhe remete aos pais e avós. Grutas, bambuzais e árvores - algumas de grande porte - são desse tempo e estão preservadas. $\mathrm{O}$ artista recicla todo o tipo de material para construir espaços de convivência, junto a parceiros, amigos, parentes e vizinhos, preferindo cozinhar em fogão a lenha e panelas de barro, de preferência as que encontra descartadas em algum lugar. Essa proximidade com a natureza é uma referência ao tempo da subsistência e da economia extrativista, como a pesca e a agricultura.
Contrapõe-se à voz da modernização, o "cantochão" do tempo presente, como uma "segunda voz", em uma espécie de movimento contrário. Quando emergem preocupações com passados (quase) extintos, “[...] o presente descobre-se igualmente em busca de raízes e de identidade preocupado com memória e genealogias" (HARTOG, 2014, p. 151). Uma espécie de "nostalgia", palavra que tem como significado "[...] a irreversibilidade do tempo: algo do passado deixa de ser acessível. [...] Mas o anseio nostálgico do passado também é sempre uma saudade de outro lugar. A nostalgia pode ser uma utopia às avessas" (HUYSSEN, 2014, p. 91).

A obra de Valdir Agostinho dialoga diretamente com a produção artística de Franklin Cascaes, importante referencial local quanto à denúncia da violenta modernização imposta à cultura popular e à natureza da Ilha de Santa Catarina. Da admiração à crítica ao cosmopolitismo artificial imposto, resulta sua percepção sobre as condições locais, expressa nas obras, a partir dos anos 1970. Ao evocar a presença de Franklin Cascaes, contrapondo-se ao desenvolvimentismo promovido no período, Reinaldo Lohn destaca,

Ao comparar as narrativas usualmente divulgadas no final do século XX com aquelas reproduzidas pela imprensa à época dos eventos mencionados, mesmo num lugar de menor importância como Florianópolis, verifica-se alguma semelhança. (LOHN, 2016, p. 120).

Algumas personagens bruxas de autoria de Cascaes puderam ser associadas às alterações no espaço urbano por meio das obras da construção civil, "a expressar o desprezo do artista pelas transformações urbanas” (LOHN, 2016, p. 130). Como artista e estudioso da cultura popular ilhoa, apresentou os efeitos da modernização em esculturas, desenhos e manuscritos.

Aos poucos, as bruxas passaram a ser relacionadas com signos da vida urbana [...]. Portanto, Cascaes abordou a modernização como uma experiência fantástica, ou seja, como um novo tipo de bruxaria que trouxera malefícios às comunidades, ao desestruturar seus 
hábitos e crenças. (LOHN, 2016, p. 138139).

Valdir Agostinho, que foi assistente de Franklin Cascaes por sete anos, certamente ficou impactado pela produção do mestre. E, em meados dos anos 1990, assumiu, nas suas obras e performances, uma postura crítica frente ao meio ambiente e à natureza, a exemplo de composições musicais como "O Rio que Corre" (1999) e "História do Lixo" (2008) $)^{15}$. Este breve histórico sobre o multiartista destina-se a fornecer elementos de compreensão sobre o recorte de sua obra apresentado neste artigo, a partir das pandorgas selecionadas e descritas.

\section{As pandorgas e Valdir}

$\mathrm{O}$ objeto tem variados nomes, e em alguns lugares do Brasil, é conhecido como pipa ou papagaio, como já declarado ao início deste texto. No entanto, na região Sul também é conhecido por pandorga. Este termo, de etimologia na língua espanhola, foi também grafado como "pandorca"16. O estudioso da cultura popular brasileira, Luís da Câmara Cascudo ${ }^{17}$, apresenta o verbete "papagaio" associado aos diferentes nomes deste artefato, também considerado como um brinquedo: "Papagaio de papel, coruja, arraia”. Para o autor, "arraia" seria o nome dado à pandorga com formato arredondado. Uma brincadeira típica documentada por Cascudo seria "guerrear nos céus", com o objetivo de roubar a pandorga, quando se rompia o fio do brinquedo do adversário, através da mistura de cola e vidro moído com a qual se impregnava a cauda ou "rabiola". Tal prática estende-se até nossos dias, conhecida por "cerol". De acordo com Raimundo Morais, citado por Cascudo, o golpe de cortar e raptar outra pipa chamar-se-ia "moquear".

Os portugueses trouxeram o papagaio do Oriente, Japão e China, onde é popular, em todas as classes sociais, desde remotíssimo tempo. Por intermédio português, como creio, ou peninsular, divulgou-se papagaio de papel pela Europa, cerf volant, barulete, cometa, kite, Hirschkäffer, Papierdrache, comum a toda a América. Do uso na China falam todos os viajantes. John Finnemore descreve uma batalha entre crianças japonesas manobrando os papagaios (Japão, cap. XIII). (CASCUDO, 1988, p. 577).

Outros nomes agregam-se ao objeto desde a Antiguidade, conforme Câmara Cascudo (1988, p. 577), "Pipas, quadrados, pandorgas, cáfilas", e teriam ainda a função de levar bilhetes, algo registrado no Brasil. A brincadeira de "passar telegrama" consistia em papeis pendurados na linha de empinar, próximos ao corpo da pipa. A prática teria sido notada pela primeira vez na China: "Dois séculos antes de Cristo, o general chinês Han-Sin utilizava o papagaio para enviar notícias a uma praça sitiada”, ou ainda, a conhecida referência histórica registrada em 1752, como um “instrumento de experimentação científica nas mãos de Benjamin Franklin” (CASCUDO, 1988, p. 577).

$\mathrm{Na}$ Barra da Lagoa - e em outras regiões do Brasil - a pandorga pode ser utilizada com outra função: servir como uma técnica de pescaria. Um espinhel é ligado à pandorga e o vento que a carrega, por sua vez, leva o espinhel mar adentro (SOARES, 2006, p. 101). Depois de certo tempo, o pescador recolhe a pandorga e confere o resultado. Para essa modalidade de pesca, é necessário ter vento soprando da terra para o mar, o vento "terral"18. A pescaria com pipas ou pandorgas é uma prática que vai além do litoral do Brasil. Em países de língua inglesa, em especial na Nova Zelândia e na Austrália, é conhecida como kite fishing. O sítio da internet Paul's Fishing Kites apresenta uma série de opções à venda, com kits variados de pandorgas com espinhel e carretilha, por exemplo. ${ }^{19} \mathrm{Na}$ ilha Tobi, no Estado de Hatohobei, na República de Palau/Micronésia, a pandorga é feita com folhas grandes de uma planta local, estruturadas com palhas da folha do coqueiro. A linha pode ser feita com a fibra da palha do coco e a isca, uma espécie de armadilha, é feita de teias de $\operatorname{aranhas}^{20}$. É possível supor que esta técnica de pescaria seja tão antiga quanto a própria pandorga. Um exemplo da importância desta prática no imaginário social foi o documentário "A pandorga e o peixe" (2014), um curta metragem contemplado 
pelo Edital Catarinense de Cinema e lançado oficialmente no $18^{\circ}$ Festival Audiovisual Mercosul (FAM), com direção e roteiro de Kátia Klock e Ivan de Sá (ROSA, 2014) ${ }^{21}$.Valdir Agostinho compôs uma canção para o documentário, que incorpora em sua letra uma oração a São Lourenço, onde roga ao santo "bons ventos" para a pesca com a pandorga: "São Lourenço, São Lourenço/Traga logo esse vento". ${ }^{22} \mathrm{O}$ objeto escolhido, brinquedo na infância e forma de manifestação na vida adulta, tornou-se sua principal forma de expressão artística. A partir de 1974, passou a competir em festivais promovidos em Florianópolis (BORTOLIN, 2010, p. 1820), recebendo premiações com pandorgas que passaram a chamar a atenção, por sua estética ou pela pluralidade de significados e temas, a exemplo de seres do mundo sobrenatural presentes na tradição local, como bruxas, lobisomens e boitatá, as belezas naturais da Ilha de Santa Catarina, ou temas do cotidiano. Destaca-se, entre as temáticas representadas, Boi-de-mamão, e seus personagens, ícone da cultural popular da Ilha de Santa Catarina. O folguedo existente em Santa Catarina assemelhase ao Bumba-meu-boi, conhecido no norte do Brasil. O termo "boi de mamão" remonta à crença de que se utilizavam mamões verdes para se fazer a cabeça do boi. "Há quem contrarie esta versão, dizendo vir o nome boi-mamão do boi que mama" (SOARES, 2006, p. 48). Os personagens principais são o boi, Mateus, Urubu, Doutor, ou Doutores e a Benzedeira $^{23}$, o Cavalinho e a Cabra (SOARES, 1978, 2006). Câmara Cascudo (1988, p. 129) aponta para o “o feiticeiro [...] que vem benzer o boi"; porém, não se tem notícia desse personagem nas performances atuais. Atualmente, existem outros animais na brincadeira, que está mais voltada às crianças, principalmente porque é um conteúdo bastante trabalhado nas escolas básicas da região. Outro destacado personagem do festejo é "a Bernúncia, que finaliza a apresentação" (CASCUDO, 1997, p. 129). Com um aspecto que lembra um dragão chinês, o monstro possui "grandes mandíbulas" e sua entrada é o ponto alto da apresentação.

A Bernúncia come gente. À sua entrada, os circunstantes debandam, mas sempre algum retadatório $[s i c]$ se deixa apanhar. Então, o indivíduo que faz a parte dianteira do bicho aciona as mandíbulas, aproveita-se do descuido, agarra o circunstante e o engole, puxando-o para dentro da goela, sob a assuada dos assistentes. (CASCUDO, 1988, p. 122).

Cascudo aponta as possíveis origens da personagem, podendo ser uma encarnação do Bicho Papão ou do basilisco" ${ }^{24}$, "[...] um bicho que veio do mar. [...] Mas a opinião geralmente aceita é a de que, de fato, o nome da fera se tenha originado da exclamação de esconjuro" (CASCUDO, 1988, p. 123). A palavra "bernúncia" seria uma variação da palavra "abrenunça", podendo ser grafada ainda como "bernunça" ou "bernunza" (HOUAISS, 2009, p. 281 ${ }^{25}$. Não por acaso, foi o termo escolhido para identificar a atual banda musical que acompanha Valdir Agostinho, conhecida por "Bernúncia Elétrica" ${ }^{26}$. $\mathrm{Na}$, temos a imagem de uma bernúncia na representação que identifica o grupo musical.

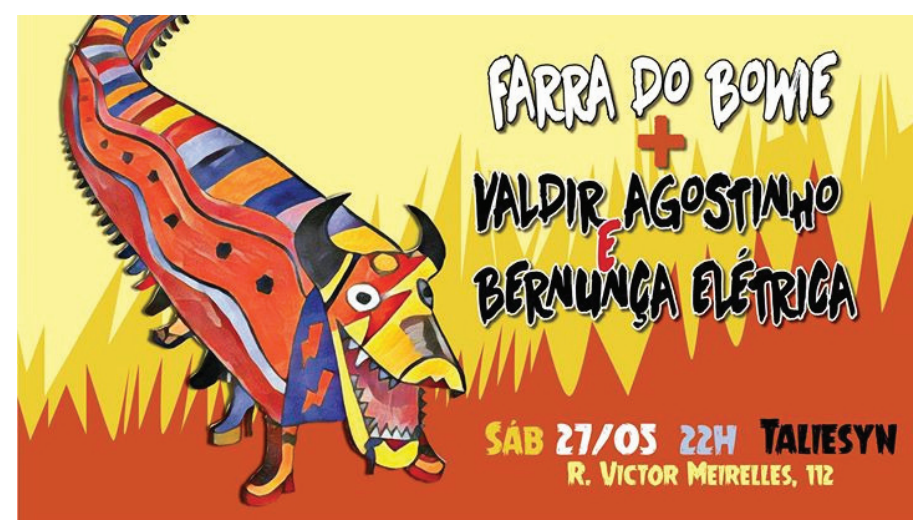

Figura 1: Cartaz desenvolvido para um show em Florianópolis Fonte: Acervo pessoal de Valdir Agostinho. 
Valdir Agostinho ficou bastante conhecido pela ação performática em suas exibições, associando a expressão plástica e musical, a partir de indumentárias características de sua personalidade. O perfil peculiar do artista foi destacado em reportagens jornalísticas.

Vestindo uma roupa especial para a ocasião, toda branca, ele empinou uma imensa pandorga de cinco metros por três, feita com papel laminado e pintura sobre pano. Para ele, soltar pipa "é um sentimento espiritual que causa emoção, fazendo esquecer a vida mecânica" (PANDORGAS..., 1987).

Não apenas empinava pipas, mas também apresentava figurinos que dialogavam com a estética das pandorgas. Encenando os movimentos do pandorgueiro, além de ajudar a mantê-las no ar, interagia com a temática e o voo, pois,

[...] vestiu-se com a estampa de sua pipa: de palhaço, e deu um show especial. Quando ele não conseguiu mais manter a pipa no ar, ele decidiu dançar e brincar com os olheiros, que formaram uma roda para apreciar o espetáculo. (FESTIVAL..., 1989).

Chegou a fazer uma fantasia que era, de fato, uma roupa de pandorga (Figura 2): "O primeiro desfile [de carnaval] foi com pandorga também, então ela vai pro palco [...] Eu sou uma pandorga [...] Tinha gente que dizia assim: 'a minha vida é uma pandorga', que eu dizia assim nas entrevistas" (AGOSTINHO, 2009a). ${ }^{27]}$

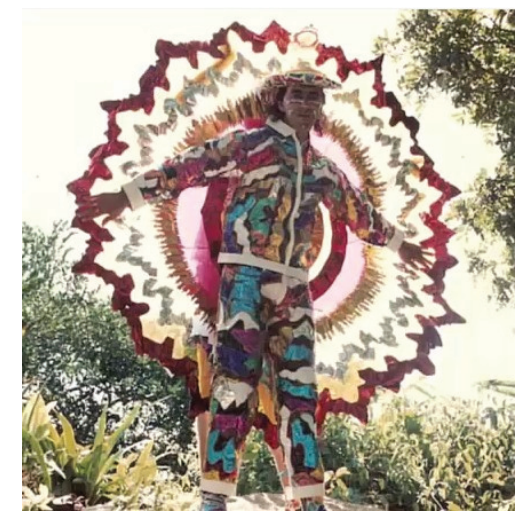

Figura 2: Valdir Agostinho e sua roupa de pandorga Fonte: Acervo pessoal de Valdir Agostinho.
As pandorgas passaram a ser exibidas em exposições de arte, individuais e coletivas. Em meados da década de 1980, desenvolvendo a ideia dos figurinos idealizados com as temáticas e materiais das pandorgas, Valdir Agostinho passou a utilizar a reciclagem de materiais como matériaprima para a confecção dos figurinos próprios e dos músicos de suas bandas, bem como outros tipos de objetos tridimensionais, como esculturas, fantasias e adereços carnavalescos. A denominação multiartista surge em documentos jornalísticos, identificados em seu acervo documental, após os anos 1990. A expressão pela música adensou-se neste período, quando a prática deixava de ser reservada ao ambiente familiar, mais íntimo, ganhando a esfera pública. Como compositor e cantor passou a apresentar-se com seu violão, individualmente, ou com outros músicos, tendo participado da banda Fênix nos anos 1980. Em 1999, lançou o CD A hora do mané, como trabalho solo.

Esta breve apresentação sobre o universo do artista e seu objeto aqui destacado, a pandorga, destina-se a subsidiar a análise de três exemplos temáticos desenvolvidos por ele. Os exemplos aqui escolhidos encontram-se registrados como reprodução fotográfica, localizados no acervo já indicado, em suporte físico.

O primeiro exemplo foi identificado por Valdir Agostinho como "O Roqueiro", espécie de representação autobiográfica, demonstrando a sua opção pela sonoridade do Rock, de data indefinida, ao final dos anos 1980 a 1990, conforme referências comentadas no decorrer deste texto. $\mathrm{O}$ segundo exemplo, intitulado "Ecologia no Ar", foi uma imagem fotográfica obtida de uma peça vencedora do concurso voltado à escolha da capa da Lista Telefônica (LISTEL) de 1990-1991, do que resulta o exemplo aqui descrito. A peça original se perdeu após o registro fotográfico, restante no acervo do artista, apenas o exemplar da Lista Telefônica. O terceiro exemplo, a pandorga "Flor de Renda", encontra-se na capa da reportagem do jornal Diário Catarinense, associada à cultura tradicional da confecção de renda de bilro.

\section{Três Pandorgas, três temáticas}

"O Roqueiro" (Figura 3) é uma fotografia do acervo pessoal de Valdir Agostinho, sem identificação do fotógrafo. Apresenta o artista caracterizado com figurino próprio ao lado da obra. 
Ele mesmo não lembra a data em que foi captada. No entanto, este objeto acompanha o artista em diferentes performances musicais, quando se apresenta com sua banda, em ambientes que sejam propícios à sua exibição. "O Roqueiro" já integrou o cenário de uma apresentação em setembro de 2013, na Casa de $\mathrm{Noca}^{28}$. Valdir Agostinho explica como as pandorgas são levadas aos shows, como parte da composição do cenário: retira a armação de bambu, ficando somente com o papel. Anteriormente costumava transportá-las em caixas menores, mas com o tempo, percebera que não era uma boa prática. "Não é mais pra ficarem dobradas, tem que ter cano [para guardá-las], tem que enrolar", explica (AGOSTINHO, 2009a). ${ }^{29}$

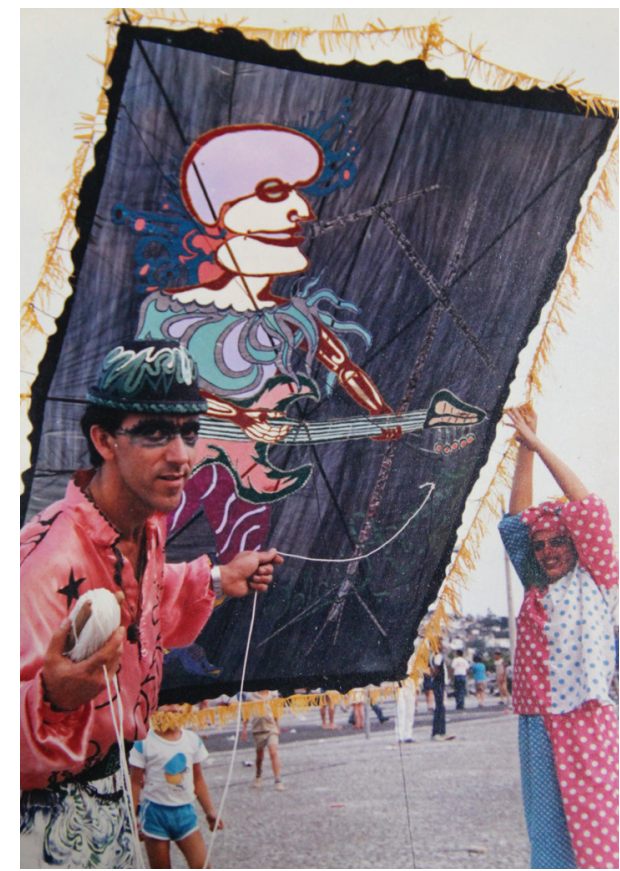

Figura 3: A pandorga “O Roqueiro"

Fonte: Acervo pessoal de Valdir Agostinho.

Apesar de todo seu envolvimento com a musicalidade típica da Barra da Lagoa, como a festa do Divino Espírito Santo, com instrumentos tradicionais como o tambor e rabeca, a presença do Boi-de-mamão e os bailes animados por seus parentes e amigos, Valdir Agostinho destaca o contato com outras experiências estético-musicais contemporâneas. A opção por tal sonoridade em suas composições, associada aos elementos da cultura açoriana local, proporcionaram produzir sua arte. O refrão de uma de suas composições, a canção "Pandorgueiro" deixa isso claro: "Só quero é pandorga e Rock and Roll para mim/A vida é tão boa há quem diga que $\operatorname{sim}^{\text {"30 }}$.Observando a fotografia descrita, $o$ artista declara que a roupa utilizada foi feita para o evento, bem como a de sua parceira. $\mathrm{Na}$ camisa cor de rosa, foi utilizada a técnica da colagem; a calça e o chapéu foram pintados. Completando o conjunto, $o$ artista apresenta maquiagem que simula o uso de óculos escuros. Sua parceira, também caracterizada, foi assim descrita na releitura da imagem, "tem uma menina de palhaço [...] que eu namorava ela, lá de Forquilhinhas" (AGOSTINHO, 2009a). ${ }^{31}$ A fotografia ativou memórias afetivas e revelou a função da indumentária, destacada pelo artista e específica para o evento. "A roupa tende, pois, a estar poderosamente associada com a memória ou, para dizer de forma mais forte, a roupa é um tipo de memória" (STALLYBRASS, 2008, p. 14).

Em 1990, Valdir Agostinho obteve o primeiro lugar na seleção para a ilustração da capa da Lista Telefônica Grande Florianópolis e Sul Catarinense: Assinantes/Classificada 90-91 (Figura 4). A tiragem foi de 104.587 exemplares, distribuídos gratuitamente aos assinantes do então serviço de telefonia da TELESC, uma empresa subsidiária da estatal Telebrás ${ }^{32}$. Neste sentido, a ilustração com a pandorga "Ecologia no Ar" esteve presente em milhares de lares e estabelecimentos do litoral catarinense. De acordo com o exemplar arquivado pelo artista:

A obra, elaborada com a técnica de desenho e colagem pelo artista plástico Valdir Agostinho, nascido em Florianópolis a 07/03/1956, procura retratar a ecologia na sua plenitude maior, oferecendo aos seres vivos a proteção do nosso ecossistema, hoje e sempre. (CASTRO, 1990, p. 2).

O uso da lista telefônica, atualmente, foi substituído como prática pelos serviços de busca via internet. No entanto, o catálogo de assinantes das linhas foi um importante objeto de conexão entre pessoas e serviços durante décadas, de uso comum. O fato de a obra "Ecologia no ar" encontrar-se impressa na capa deste veículo proporcionou ao artista ser conhecido fora de Florianópolis e em outras regiões de Santa Catarina. 
Em função do processo de privatização desenvolvido no Brasil durante a gestão do Presidente Fernando Henrique Cardoso, a Telesc deixou de ser uma empresa pública estatal ao final da década de 1990. Em função disso, as listas telefônicas originalmente fornecidas deixaram de ser entregues e tornaram-se obsoletas a partir das novas tecnologias de informação e comunicação. Permanece, então, o questionamento quanto aos serviços prestados pela Listel Editora, empresa responsável pela edição das listagens. Segundo Valdir Agostinho, a obra original que deu origem a reprodução fotográfica inserida na capa da Lista citada, deveria ser localizada "na sala do presidente da Listel" (AGOSTINHO, 2009a). ${ }^{33}$ Diante do desaparecimento da empresa, a obra igualmente se perdeu. Ao mencionar a pandorga "Ecologia no Ar", ele lembra o quanto foi incentivado pelo já reconhecido artista local, Hassis ${ }^{34}$. Diante do estímulo proporcionado pelo experiente colega, Valdir Agostinho foi tomado por um intenso processo criativo: ficava horas em sua loja, a molduraria no Centro da cidade, de portas fechadas, deixando de atender sua clientela para trabalhar na obra. Hassis também sugeriu a colocação da pandorga em uma tela com fundo remetendo à imagem de um céu, dando a impressão que estivesse voando. A ideia rendeu muitos quadros produzidos por Valdir Agostinho, de tamanho pequeno, com "minipandorgas" colocadas sobre a tela. Segundo ele, ainda tem alguns em seu acervo, pois muitos destes quadrinhos teriam sido vendidos, outros foram doados, além dos que se perderam.

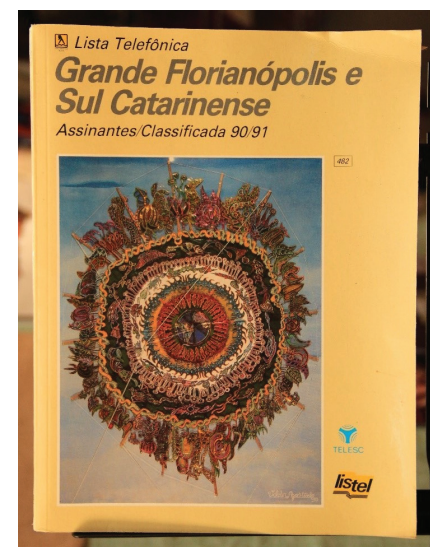

Figura 4: Capa da Lista Telefônica 1990/1991. Fonte: ? Acervo pessoal de Valdir Agostinho.
$\mathrm{Na}$ observação da imagem, em detalhe, é possível perceber a Terra no centro de uma série de níveis concêntricos, similares aos esquemas cosmográficos medievais, "cercada de círculos concêntricos onde estão figurados os quatro elementos, os sete planetas [...], os signos do Zodíaco e as estações e as fases da Lua" (COSTA, 2002, p. 482). Em um esquema muito semelhante, a Terra está cercada de uma cor vermelha, que remete ao fogo, à lava. Observando do centro para a borda, denota-se uma faixa mais amarelada, remetendo ao solo, envolto, por sua vez, em uma cor azulada com formas que se assemelham à água, ao mar e suas ondas. Em cada faixa representada constam seres vivos, entre fauna e flora. O artista, ao rever a capa da Lista Telefônica, comenta sobre a pandorga: "[...] o Sol em volta da Terra, e muito mais coisas em volta da Terra, as plantas, e termina com a ecologia. A Terra toda encapada com a ecologia. [...] Todo esculpido, o papel" (AGOSTINHO, 2009a). ${ }^{35} \mathrm{~A}$ ilustração da capa da Lista Telefônica, a pandorga "Ecologia no Ar" surge como resultado de um registro fotográfico. Do objeto original permaneceu apenas a fotografia. A partir daí, estabeleceu-se um processo de ruptura e esvaziamento da obra, pois deixou de existir no contexto original de produção, constituindo-se em sua reproduçãa ${ }^{36}$. Nesta condição, todas as inferências que resultam da apreciação desta pandorga partem da capa da Lista Telefônica. Um objeto que aponta para o esvaziamento de uma obra que, primeiramente, foi registrada e é uma reprodução da obra original; segundo, uma pandorga que se perdeu e que pode até ter deixado de existir. Poder-se-ia dizer, "é apenas uma lista telefônica velha e sem utilidade", ou "é apenas um pedaço de papel”, mas não passaria de "uma verdade rasa", utilizando a expressão de DidiHuberman, negando, então, que o objeto também nos olha. Em uma vitória da "[...] linguagem sobre o olhar, na afirmação fechada, congelada, de que aí não há nada mais do que um volume, e que esse volume não é senão ele mesmo" (DIDI-HUBERMAN, 1998, p. 39), estaríamos desprezando a possibilidade de apreciar a obra de arte em questão, mesmo que em uma reprodução. 


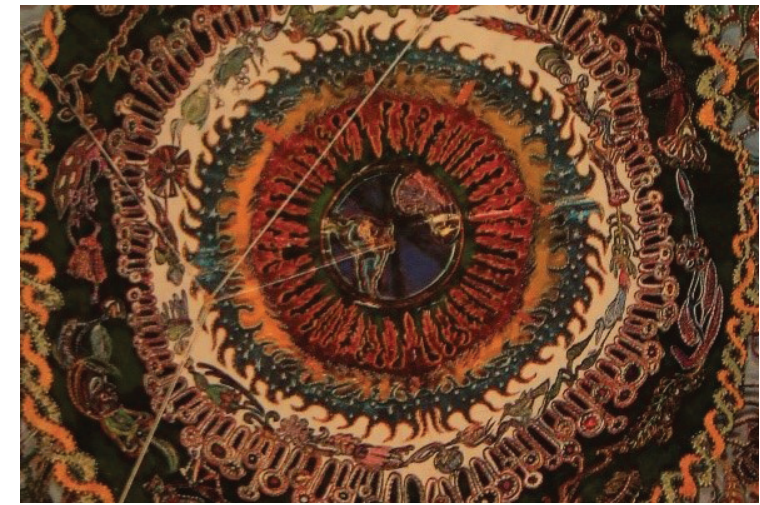

Figura 5: Detalhe da pandorga.

Fonte: Acervo pessoal de Valdir Agostinho

A pandorga "Flor de Renda" (Figura 6), também permaneceu somente no registro fotográfico. Foi capa do suplemento Revista DC, do jornal Diário Catarinense, a partir do fotógrafo Carlos Kilian. A matéria intitulada "Rumo ao infinito" informava ao leitor sobre a importância das pandorgas na vida de Valdir Agostinho.

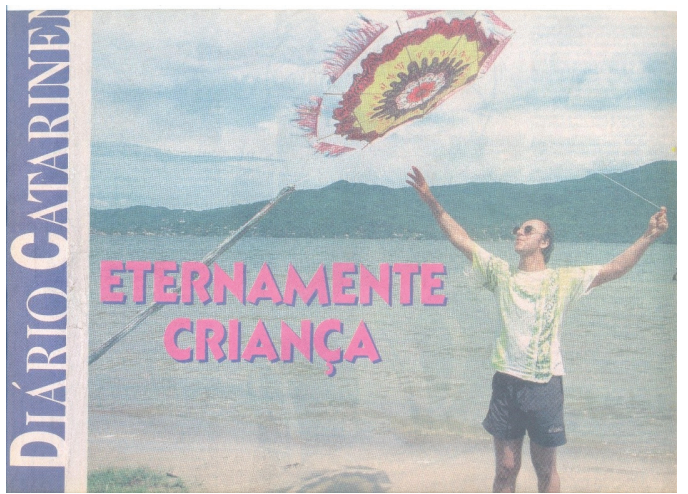

Figura 6: Foto no jornal Diário Catarinense, com a pandorga Flor de Renda Fonte: Carlos Kilian (1998).

Adriana Baldissarelli, nesta matéria, atribuilhe os títulos de "folclorista" e "mestre" da pandorga, quando apresenta o seguinte relato:

A diversão de sua infância virou hábito, profissão, obra de arte. "O que fascina é a maneira de soltar a pandorga: a sensação de se sentir solto no espaço junto com ela. Parece que também a alma da gente está livre, vagando pelos mistérios do céu", afirma Agostinho. Desde criança, ele faz pandorgas: foi seu primeiro brinquedo e aquele que mais o interessou. (BALDISSARELI, 1998, p. 8).
Esta também é uma obra que não se encontra no acervo do artista, o qual pensa que doou para alguém, logo após a sessão de fotos para a reportagem. "Flor de Renda" no suporte documental em que se encontra, pôde tornar-se parte da análise deste trabalho. Como fonte da pesquisa, na imagem registrada e no arquivo digitalizado, remete à história do objeto que possibilitou inserir a ação do artista e seu resultado, no tempo e no espaço.

A história sempre foi história apenas daqueles que "fazem história". O que muda é a identidade dos "fazedores de história”. E a era da história é aquela em que qualquer um pode fazê-la, porque todos já a fazem, porque todos já são feitos por ela. (RANCIĖRE, 2018, p. 19).

O tempo da experiência, em Valdir Agostinho, foi marcado também pelo desenvolvimento de oficinas de arte com crianças em escolas de educação básica. Essa demanda surgiu do amadurecimento do artista na sua atividade. Sobre isso, declarou: "Das crianças virem falar comigo, de eu me sentir uma criança até hoje, isso me renovou. [...] Eu tenho esse lado moleque da pandorga e isso vai ficar comigo, eterno. A pandorga vai ser jovem $o$ resto da vida" (AGOSTINHO, 2009a). ${ }^{37}$ Valdir Agostinho assumia assim a identidade de sua obra, a partir dos objetos produzidos.

\section{Considerações finais}

Ao realizar a pesquisa com as fontes documentais encontradas no acervo do artista, bem como o trabalho com as entrevistas seguindo a metodologia da História oral, foi possível perceber a formação de um universo particular do artista. Este universo pode ser compreendido a partir de dois vínculos: um deles está relacionado com o seu modo de vida, o outro, à sua obra.

A pandorga conecta o artista a uma espécie de "alter-ego" e permite a construção de uma experiência individual, situada entre os ambientes rural e urbano, muito mais contrastantes na Florianópolis dos anos 1970 do que atualmente. Esse convívio, além de ser contrastante no que diz respeito ao espaço físico e geográfico, 
relaciona-se também com um espaço "imaterial", ou seja, a cultura, transitando entre tradição e cosmopolitismo. Tal experiência lhe conferiu uma perspectiva ambiental e ecológica, a partir da ida para o Centro da cidade e de seu retorno para a Barra da Lagoa, para viver uma vida "simples". O contato com o cosmopolitismo promoveu uma consciência do século $\mathrm{XX}$, ou seja, as consequências do progresso, como poluição, destruição, preconceito e uma espécie de "apagamento da memória", ou de determinadas memórias, permitindo que somente algumas permaneçam, seja por usos políticos ou econômicos.

O trabalho como assistente de Franklin Cascaes permitiu uma aproximação com a obra do então "mestre". Cascaes denunciava a destruição dos prédios históricos do Centro da cidade e valorizava a cultura popular, o que foi comentado nas colunas de Beto Stodieck, uma vez que o Studio A/2 ajudou a promover os Presépios de Cascaes, de acordo com nota no jornal O Estado, em 28 de dezembro de 1976 (PORTO; LAGO, 1999, p. 166). Depois de uma trajetória percorrida, Valdir Agostinho passa de discípulo a mestre, reconhecido como folclorista e seguindo os passos de Franklin Cascaes. O artista, assim como seu mestre, estuda a cultura popular e problematiza a relação humana com a natureza, as praias e o meio ambiente como um todo.

Com a análise das pandorgas selecionadas para este artigo, constata-se que: 1) a pandorga "O Roqueiro" leva o artista em direção à modernidade e a um afastamento da tradição; 2) A partir do apoio dado por Hassis, um artista mais experiente, o jovem Valdir Agostinho começa a se definir enquanto profissional das artes visuais e a optar pelo tema da ecologia, o que fica evidenciado pelo próprio título da pandorga, "Ecologia no ar"; 3) por fim, na pandorga "Flor de Renda", percebe-se como a identidade do artista se constrói em torno de sua obra, produzindo um diário pessoal "visual", a partir de suas pandorgas, de sua música, seus figurinos e de sua arte visual reciclada. Dessa forma, o folclorista se consolida, passando de discípulo a mestre.

Todas essas experiências, vindas de trânsitos espaciais e sociais, permitiram a Valdir Agostinho criar um campo para a produção de sua arte. Analisar uma obra de arte nos remete “[...] ao mundo social no qual foi produzida e que ela traz à luz. Obriga a interrogar-se sobre as condições sociais particulares que estão na origem da lucidez especial" do artista "[...] e também dos limites dessa lucidez" (BOURDIEU, 2005, p. 63). Ao analisar a gênese do campo literário de Flaubert, é possível compreender sua "fórmula geradora", proveniente da "estrutura social da qual é o produto" (BOURDIEU, 2005, p. 63). A obra de Valdir faz referência a forças poderosas e critica a especulação imobiliária, o avanço do progresso e sua pesada conta. Assim como Franklin Cascaes, busca em um tempo passado o equilíbrio entre a natureza e os seres humanos.

Uma fuga do tempo em crise? Em sua propriedade, Valdir Agostinho vive como se estivesse em outro tempo, outro ritmo. Mas é um simulacro: suas casas se transformaram em uma fonte de renda, e parece que não é possível sobreviver exclusivamente de sua arte. Um preço a pagar para manter firme suas convicções.

\section{Notas}

1 De acordo com o Dicionário Houaiss da língua portuguesa (HOUAISS; VILLAR, 2009, p. 1496), o substantivo feminino "pipa" tem as seguintes acepções: 1. "recipiente bojudo de madeira, para líquidos", como vinhos; 2. "jocoso. pessoa gorda e de baixa estatura"; 3. "antiga unidade de medida para líquidos equivalente a 4,972 hectolitros"; 4. O mesmo que "papagaio ('brinquedo')"; 5. "pessoa que bebe em excesso; beberrão, ébrio".

2 Mandala é um "[...] diagrama composto de formas geométricas concêntricas, utilizado no hinduísmo, no budismo, nas práticas psicofísicas da ioga e no tantrismo como objeto ritualístico e ponto focal para meditação". A etimologia vem do sânscrito: "mandala 'círculo', p.ext. "linha fechada em círculo que simboliza o universo"” (HOUAISS, 2009, p. 1229).

3 A comunidade do Morro do Mocotó localiza-se no Maciço do Morro da Cruz, no Centro de Florianópolis. A ocupação humana na comunidade ocorreu durante os séculos XVIII e XIX. Era chamado de Morro do Governo e ficou conhecido pelas mulheres, reconhecidas cozinheiras, requisitadas como empregadas de "políticos, governantes, deputados e juízes da cidade. Na época da construção da Ponte da Independência [posteriormente batizada de Ponte Hercílio Luz], as cozinheiras preparavam Mocotó para vender aos 
trabalhadores da ponte - essa é a origem do outro nome do Morro" (SANTOS, 2009, p. 602). Além de ser um refúgio de escravos, fugidos e libertos, também recebia [...] "os pobres que eram afastados do Centro para dar inícios às obras de modernização da cidade, realizadas principalmente no século XX" (GONÇALVES, 2015, p. 25).

4 Os trechos extraídos das entrevistas foram mantidos sem correções gramaticais. Relato do dia 22 de janeiro de 2019 (10 min e 55 s.).

5 "Portfólio" é uma palavra que designa o "conjunto de trabalhos de um artista, ou de fotos de ator ou modelo, ou de anúncios de uma agência us. para divulgação; buque". Do inglês, "pasta para carregar papéis" (HOUAISS, 2009, p. 1528).

6 "Patrão", como um termo de marinha, significa "Chefe da guarnição de embarcação pequena a remos ou a motor" (HOUAISS, 2009, p. 1447). O sentido empregado por Valdir é de proprietário da embarcação, o qual recebe uma quantia maior do pescado.

7 Bairro localizado na Baía Sul da Ilha de Santa Catarina, próximo ao Centro de Florianópolis.

8 Relato do dia 05 de setembro de 2018 ( 24 min 41 s).

9 Relato do dia 05 de setembro de 2018 (25 min 14 s).

10 Relato do dia 05 de setembro de 2018 (26 min 53 s).

11 Sérgio Roberto Leite Stodieck (1946-1990) foi jornalista e colunista atuante nas décadas de 1970 e 1980. Em 11 de julho de 1971, estreou sua coluna no jornal "O Estado" (FONSECA, 2008, p. 16). Nascido em Blumenau/ SC, cursou a faculdade de Direito do Rio de Janeiro, “[...] cidade onde também começa sua carreira jornalística no 'O Jornal', dos Diários Associados. [...] Beto Stodieck cruzou mundos e através de suas colunas diárias trouxe para a juventude de Florianópolis seu ar cosmopolita" (ANDRADE, 2010, p. 47-48).

12 Relato do dia 22 de janeiro de 2019 (9 min e 10 s.).

13 Relato do dia 28 de janeiro de 2019 (30 min e 54 s.).

14 "Bambuzal": "extenso aglomerado de bambus em determinada área; bamburral, bambuzal” (HOUAISS, 2009, p. 251). Obambu é uma “[...] gramínea caracterizada pelo colmo que atinge muitos metros de altura. [...] De origem malaia, mas de étimo mal determinado", século XVII (CUNHA, 2010, p. 78).

15 As canções "O rio que corre" e "História do Lixo" são de autoria de Valdir Agostinho. A primeira foi consultada a partir da faixa 5 do CD "A hora do Mané". A segunda canção está disponível em: https://www.youtube.com/

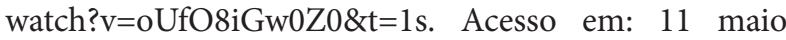
2019.

$16 \mathrm{O}$ verbete "pandorga" apresenta diferentes acepções, como "música sem ritmo e ruidosa"; "mulher gorda"; no Brasil, "papagaio de papel” (HOUAISS, 2009, p. 1421).
O Dicionário Priberam da Língua Portuguesa (2013) acrescenta: "Brinquedo de papel ou de paninho, de forma oval, triangular ou quadrangular, que se lança ao vento, ficando preso por uma guita. = PIPA Sinônimo Geral: PANDORCA". A etimologia data de 1656, do castelhano, derivado do verbo "pandorgar" e, este, do latim vulgar, "pandoricare" (CUNHA, 2010, p. 473).

17 Luís da Câmara Cascudo (1898-1963) foi um folclorista e estudioso da cultura popular brasileira. Jornalista, estreou "publicando artigo no periódico $A$ Imprensa, de Natal (1914-1927), de propriedade do pai”. Formou-se bacharel em direto (1928). "Professor de Direito Internacional Público da Faculdade de Direito e de Etnologia Geral da Faculdade de Filosofia, do Rio Grande do Norte. [...] Publicou 48 volumes e 44 ensaios". (MENEZES, 1978, p. 177).

18 Terral: de modo geral, vento que sopra da terra para o mar; "na Índia, diz-se da estação em que predomina o vento que sopra da terra" (HOUAISS, 2009, p. 1835).

19 Disponível em: http://www.fishingkites.co.nz/ htmfiles/kite.htm. Acesso em: 12 jan. 2019.

20 Disponível em: https://en.m.wikipedia.org/wiki/Kite_ fishing. Acesso em: 12 jan. 2019.

21 Disponíveis na Internet o trailer do documentário e ao clipe da música "São Lourenço" em: https://vimeo. com/96002092; https://vimeo.com/96002093. Acesso em: 23 mar. 2019.

22 Essa canção, além de integrar a trilha sonora do filme "A pandorga e o peixe" (2014), faz parte do repertório da banda Bernúncia Elétrica, que acompanha o artista.

23 Benzedeira deriva do verbo "benzer", que significa "consagrar ao culto divino ou chamar o favor do céu", com etimologia datada do séc. XVI, derivado do latim "běnědīcěre", que significa "abençoar". Por extensão, "benzedeira" é quem intercede ao culto do divino e dos favores do céu. Benzedeira e benzedura tem sua etimologia datada em 1813 (CUNHA, 2010, p. 87).

24 Basilisco: "réptil fantástico em forma de serpente", etimologia registrada no séc. XII. "Do lat. basiliscus -i, deriv. do gr. basilískos 'reizinho' 'réptil' 'certo peixe do mar"” (CUNHA, 2010, p. 83).

25 A palavra "bernúncia", ou "abrenunça", menos corriqueira, tem sua etimologia na palavra "abrenunciação", que significa "renúncia, repulsa", com etimologia oriunda do latim e datada do séc. XVIII" (CUNHA, 2010, p. 4).

26 Em 2010, o nome da banda era "Valdir Agostinho e a Conspiração Mané”. Entretanto, descobriu-se que já existia uma banda com este nome. Jorge Goméz, baixista na ocasião, sugeriu o título de uma canção de sua autoria, "Bernúncia Elétrica", o que foi aceito unanimemente. Atualmente, a banda está com suas atividades reduzidas, desde o falecimento do então baterista Nicolas Malhomme (1961-2018). 
27 Relato do dia 22 de janeiro de 2019 (17 min e 26 s.).

28 A Casa de Noca era um espaço da noite de Florianópolis, localizado na Avenida das Rendeiras, Lagoa da Conceição, Florianópolis/SC. De acordo com arquivo audiovisual do acervo da banda e disponível na internet, o documento foi produzido por Guilherme Ledoux. Disponível em: https://www.youtube.com/ watch? $v=s 75 j$ Cgsxi5U\&t=241s. Acesso em: 25 fev. 2019.

29 Relato do dia 22 de janeiro de 2019 (26 min e 8 s.).

30 Faixa 1 do CD "A hora do Mané”.

31 Relato do dia 22 de janeiro de 2019 (25 min e 23 s.).

32 É difícil saber a partir de quando a Listel deixou de fornecer o serviço de listas telefônicas impressas. Em uma pesquisa à internet, o que se pôde encontrar foi o verbete "Lista telefônica" da Wikipédia, que trata do tema como um todo. Destaca que "O Brasil possui inúmeras empresas publicadoras de listas telefônicas, sendo algumas: Guiatel, LTB Lista Telefônica Brasil, Lista Mais, Superlista, VerFone, Guia Fácil, Telelistas, MinhaBoituva, Lista telefônica, EPIL, Guia Mais, Ache Certo, Lista BR, Lista Metropolitana e Listel”. Disponível em: https:// pt.wikipedia.org/wiki/Lista_telefônica. Acesso em: 20 maio 2019.

33 Relato do dia 22 de janeiro de 2019 (36 min e 7 s).

34 Hiedy de Assis Correa, ou Hassis, (1926 - 2001) foi pintor, desenhista e ilustrador autodidata. Passou a residir em Florianópolis em 1944. Em 1966, "criou desenhos motivados no folclore da Ilha de Santa Catarina, em mosaico português para cinco praças públicas de Florianópolis" (BORTOLIN, 2010, p. 197). Uma delas é a Praça XV de Novembro, no Centro da cidade.

35 Relato do dia 22 de janeiro de 2019 (36 min e 19 s).

36 Conforme Walter Benjamin: "A obra de arte na era de sua reprodutibilidade técnica”.

37 Relato do dia 22 de janeiro de 2019 (16 min e 38 s).

\section{Referências}

AGOSTINHO, Valdir. Entrevista concedida a Luciano Py de Oliveira, Florianópolis, 5 set. 2018. [Transcrição impressa do documento em áudio digital, acervo do pesquisador].

AGOSTINHO, Valdir. Entrevista concedida a Luciano Py de Oliveira, Florianópolis, 22 jan. 2019a. [Documento em áudio digital, acervo do pesquisador].

AGOSTINHO, Valdir. Entrevista concedida a Luciano Py de Oliveira, Florianópolis, 28 jan. 2019b. [Documento em áudio digital, acervo do pesquisador].

ALBERTI, Verena. Manual de história oral. 3. ed. Rio de Janeiro: Editora FGV, 2013.

ANDRADE, Ana Luíza Mello Santiago de. Entre saias de pregas e calças compridas: a coeducação no Colégio Coração de Jesus (1971-1978). Orientador: Maria Teresa Santos Cunha. 2010. 102 f. Trabalho de Conclusão de Curso (Licenciatura em História) - Centro de Ciências Humanas e da Educação, Universidade do Estado de Santa Catarina, Florianópolis, 2010.

ARTIÈRES, Philippe. Arquivar a própria vida. Revista Estudos Históricos, Rio de Janeiro, v. 11, n. 21, jul. 1998. Disponível em: http://bibliotecadigital. fgv.br/ojs/index.php/reh/article/view/2061. Acesso em: 17 jun. 2017.

ASSMAN, Aleida. Espaços de recordação: formas e transformações da memória cultural. Tradução de Paulo Soethe. Campinas: Editora da Unicamp, 2011.

BALDISSARELLI, Adriana. Rumo ao infinito. Diário Catarinense, Florianópolis, 15 fev. 1998, p. 8.

BORTOLIN, Nancy Therezinha. Indicador catarinense de artes plásticas: verbetes de referência curricular. Florianópolis: Museu de Arte de Santa Catarina, 2010. Disponível em: http://www.cultura. sc.gov.br/espacos/masc/indicador-catarinense-dasartes-plasticas. Acesso em: 7 mar. 2019.

BOURDIEU, Pierre. As regras da arte: gênese e estrutura do campo literário. 2 ed. São Paulo: Companhia das Letras, 2005.

CASCUDO, Luís da Câmara. Dicionário do folclore brasileiro. 6. ed. Belo Horizonte: Editora Itatiaia, 1988.

CASTRO, Wanderley Gregoriano de (Ed.). Lista Telefônica Grande Florianópolis e Sul do Estado: Assinantes/Classificada 90/91, ano XVII, n. 4. Florianópolis: Listel - Listas Telefônicas S.A., 1990.

COSTA, Ricardo da. Olhando para as estrelas, a fronteira imaginária final: astronomia e astrologia 
na Idade Média e a visão medieval do cosmo. Dimensões, v. 14, p. 481-501, 2002.

CUNHA, Antônio Geraldo. Dicionário etimológico da língua portuguesa. 4. ed. rev. e aum. Rio de Janeiro: Lexikon Editora Digital Ltda., 2010. E-book. [fac-símile]

\section{DICIONÁRIO PRIBERAM DA LÍNGUA} PORTUGUESA. Lisboa: Priberam Informática, 2008-2013. Disponível em: https://dicionario. priberam.org. Acesso em: 15 maio 2019.

DIDI-HUBERMAN, Georges. O que vemos, o que nos olha. São Paulo: Ed. 34, 1998.

FESTIVAL de pandorga coloriu Florianópolis. O Estado, Florianópolis, 5 set. 1989.

FONSECA, Jefferson Rafael da. Nossa Senhora do Aterro: Florianópolis a partir das crônicas ligeiras de Beto Stodieck (1971-1980). Orientadora: Sandra J. Pesavento. 2008. 165 f. Dissertação (Mestrado em História) - Programa de Pós-Graduação em História, Universidade federal do Rio Grande do Sul, Porto Alegre, 2008. Disponível em: http://hdl. handle.net/10183/21516. Acesso em 10 maio 2019.

GONÇALVES, Beatrice Corrêa de Oliveira. O ensopado que alimenta, identifica e dá nome ao Morro do Mocotó - Florianópolis, SC. Orientadora: Carmen Sílvia de Moraes Rial. 2015. 106 f. Dissertação (Mestrado em Antropologia Social) - Programa de PósGraduação em Antropologia Social, Universidade Federal de Santa Catarina, Florianópolis, 2015. Disponível em: https://repositorio.ufsc.br/xmlui/ handle/123456789/160780. Acesso em: 12 maio 2019.

HARTOG, François. Regimes de historicidade: presentismo e experiências do tempo. Tradução de Wilma Patrícia Maas; Carlos Almeida Pereira. Belo Horizonte: Autêntica Editora, 2014.

HOUAISS, Antônio; VILLAR, Mauro de Salles. Dicionário Houaiss da língua portuguesa. Rio de Janeiro: Objetiva, 2009.
HUYSSEN, Andreas. Culturas do passadopresente: modernismos, artes visuais, políticas da memória. Tradução: Vera Ribeiro. Rio de Janeiro: Contraponto/Museu de Arte do Rio, 2014.

KOSELLECK, Reinhardt. Futuro passado: contribuição à semântica dos tempos históricos. Tradução de Wilma Patrícia Haas; Carlos Almeida Pereira. Rio de Janeiro: Editora da PUC-Rio, 2006.

LOHN, Reinaldo Lindolfo. Artífices do futuro: cultura política e a invenção do tempo presente de Florianópolis (1950-1980). Florianópolis: Editora Insular, 2016.

MENEZES, Raimundo de. Dicionário literário brasileiro. 2. ed. rev. e aum. Rio de Janeiro: Livros Técnicos e Científicos, 1978.

PANDORGAS na Baía Sul. O Estado, Florianópolis, 31 ago. 1987.

PORTO, Beatriz; LAGO, Fernanda. É tudo mentira: a história segundo Beto Stodieck. Florianópolis: Verde Água Produções Culturais, 1999.

RANCIÈRE, Jacques. Figuras da história. Tradução de Fernando Santos. São Paulo: Editora Unesp, 2018 .

ROSA, Edson. Documentário resgata tradicional pescaria de espinhel com pandorga na praia do Campeche, na Ilha. Notícias do Dia Online, Florianópolis, 20 mai. 2014. Disponível em: <http:// ndonline.com.br/florianopolis/noticias/167905documentario-resgata-tradicional-pescaria-deespinhel-com-pandorga-na-praia-do-campechena-ilha.html>. Acesso em: 21 jul. 2016.

SANTOS, André Luiz. Do Mar ao Morro: a geografia histórica da pobreza urbana em Florianópolis. Orientador: Élson Manoel Pereira. 2009. 658 f. Tese (Doutorado em Geografia) - Programa de Pós-Graduação em Geografia, Universidade Federal de Santa Catarina, Florianópolis, 2009. Disponível em: http://repositorio.ufsc.br/xmlui/ handle/123456789/92552. Acesso em: 12 maio 2019. 
STALLYBRASS, Peter. O casaco de Marx: roupas, memória, dor. 3. ed. Organização e tradução de Tomaz Tadeu. Belo Horizonte: Autêntica Editora, 2008.
SOARES, Doralécio. Boi-de-mamão catarinense. Cadernos de Folclore 27. Rio de Janeiro: FUNARTE, 1978.

SOARES, Doralécio. Folclore catarinense. 2. ed. Florianópolis: Editora da UFSC, 2006. 